\title{
Use of Sensor Technologies in Online Courses in Post-COVID-19 Era
}

\author{
Tung-Lung Wu, ${ }^{1}$ Ming-Yuan Hsieh, ${ }^{2 *}$ Kao-Wei Min, ${ }^{3}$ Ming-Ta Yu, ${ }^{4}$ and Chi-Ting $\mathrm{Ho}^{4}$ \\ ${ }^{1}$ School of Mechanical and Automotive Engineering, Zhaoqing University, \\ Zhaoqing 516260, Guangdong, China \\ ${ }^{2}$ Department of International Business, National Taichung University of Education, \\ Taichung City 40306, Taiwan (R.O.C.) \\ ${ }^{3}$ College of Engineering, National Formosa University, Huwei, Yunlin 632, Taiwan \\ ${ }^{4}$ Department of Mechanical Design Engineering, National Formosa University, \\ Huwei, Yunlin 632, Taiwan
}

(Received December 31, 2020; accepted April 19, 2021)

Keywords: sensor technology, online-course technology, Massive Open Online Courses (MOOCs), multiple-criteria decision-making (MCDM) methodology

In this study, educational social learning theory and a statistical multiple-criteria decisionmaking (MCDM) methodology are creatively cross-employed to comprehensively cross-evaluate online courses and sensor technologies. This was accomplished by means of an in-depth survey of large-scale current online-course users and professional experts with the highest research reliability, validity, accuracy, and representativeness. The three most valuable and contributive conclusions of this study are as follows: (1) The repurposing technology function (RTF) of online-course technology can combine software sensor (SS), motion sensor (MS), and environment sensor (ES) technologies to not only detect moving objects but also achieve cognition in the environment (e.g., by using a face sensor) to extract emotions of course participants in response to words and phrases during lectures to increase online-course learning performance. (2) The course professionalization technology function (CPTF) of online-course technology can merge SS, MS, and ES technologies to control online-course hardware sensor devices and equipment to control the depth and span of online-course content to strengthen online-course learning performance. (3) The course evaluation technology function (CETF) of online-course technology can consolidate SS, MS, and ES technologies to not only empirically evaluate online-course implementation but also indirectly appraise online-course learning performance.

\section{Introduction}

In the official announcement of the World Health Organization on March 11, 2020, the spread of the coronavirus disease 2019 (COVID-19) was characterized as a global pandemic. Moreover, the COVID-19 outbreak increased the unemployment rate globally, with up to 23 million people

*Corresponding author: e-mail: uscpawisely@hotmail.com https://doi.org/10.18494/SAM.2021.3287 
laid off at one point in the USA according to the official report from Bridgewater Associates. COVID-19 has also had a sizable impact on countries' economies, with considerable declines in the gross domestic product, such as a drop of 20\% for Germany. COVID-19 has led to the unprecedented closing of national borders and rules on the movement of people. According to a Taiwanese statistical report, approximately 11\% (1.2 million) of Taiwanese workers have been laid off since the start of the pandemic. To avoid large-scale COVID-19 infections, educational institutions across the world have shifted to online courses to replace traditional face-to-face teaching. Many renowned colleges and universities such as Harvard University, Princeton University, Columbia University, Massachusetts Institute of Technology, and University of Cambridge have instituted a series of online-course emergency measures in place of current face-to-face courses. The Ministry of Education in Taiwan has started a series of measures to support online courses, as well as policies and regulations to ensure students' right to education while minimizing the risk of becoming infected with COVID-19. National Tsing Hua University in Taiwan was one of the first institutions to commence online teaching on March 24, 2020 after 26 students and one professor came in contact with a confirmed COVID-19 patient. National Chengchi University in Taiwan has also made the transition from face-to-face courses to online teaching.

However, according to the official Teaching and Learning International Survey of the Organization for Economic Cooperation and Development (OECD) in 2018, only 15\% of Taiwanese junior high schools have utilized information and communication technology in their teaching, compared with an average of 53\% among the OECD members. In 2000, the Ministry of Education in Taiwan started to advocate the use of diversified technologies (such as information technology, digital technology, and wireless technology) as alternatives to the oneway flow of information from teachers to students. As shown in the 2020 empirical reports from the Department of Information and Technological Education of the Ministry of Education in Taiwan, there were 341 online courses in the official Massive Open Online Courses (MOOCs) provided by 63 Taiwanese universities and colleges in 2018. An overview of some Taiwanese MOOC websites is presented in Table . $^{(1)}$

Specifically, according to official reports from the Department of Information and Technological Education of the Ministry of Education in Taiwan in 2020 after the COVID-19 outbreak, only $12 \%$ of registered users of Taiwanese MOOCs could obtain official certificates for online-course credits and degrees through the diverse applied Internet of Things (IoT) platforms. There are five main reasons for this. ${ }^{(2)}$ First, teachers are not willing to redesign course contents for online learning on IoT platforms because of numerous course copyright issues. Second, teachers are not willing to acquire the necessary proficiency in using the new technologies for online courses on IoT platforms because they lack the time and resources to digitalize the original documentation of their courses. Third, it is difficult to evaluate students' attendance in an online environment through IoT platforms because there are many technological issues. Fourth, it is difficult for parents to assess a student's learning performance when using an IoT platform because of personal privacy issues. Finally, companies have reservations regarding the student evaluation system employed with online courses on IoT platforms because of privacy issues of course participants. To effectively solve these critical issues to strengthen students' 
Table 1

Overview of Taiwanese MOOC websites.

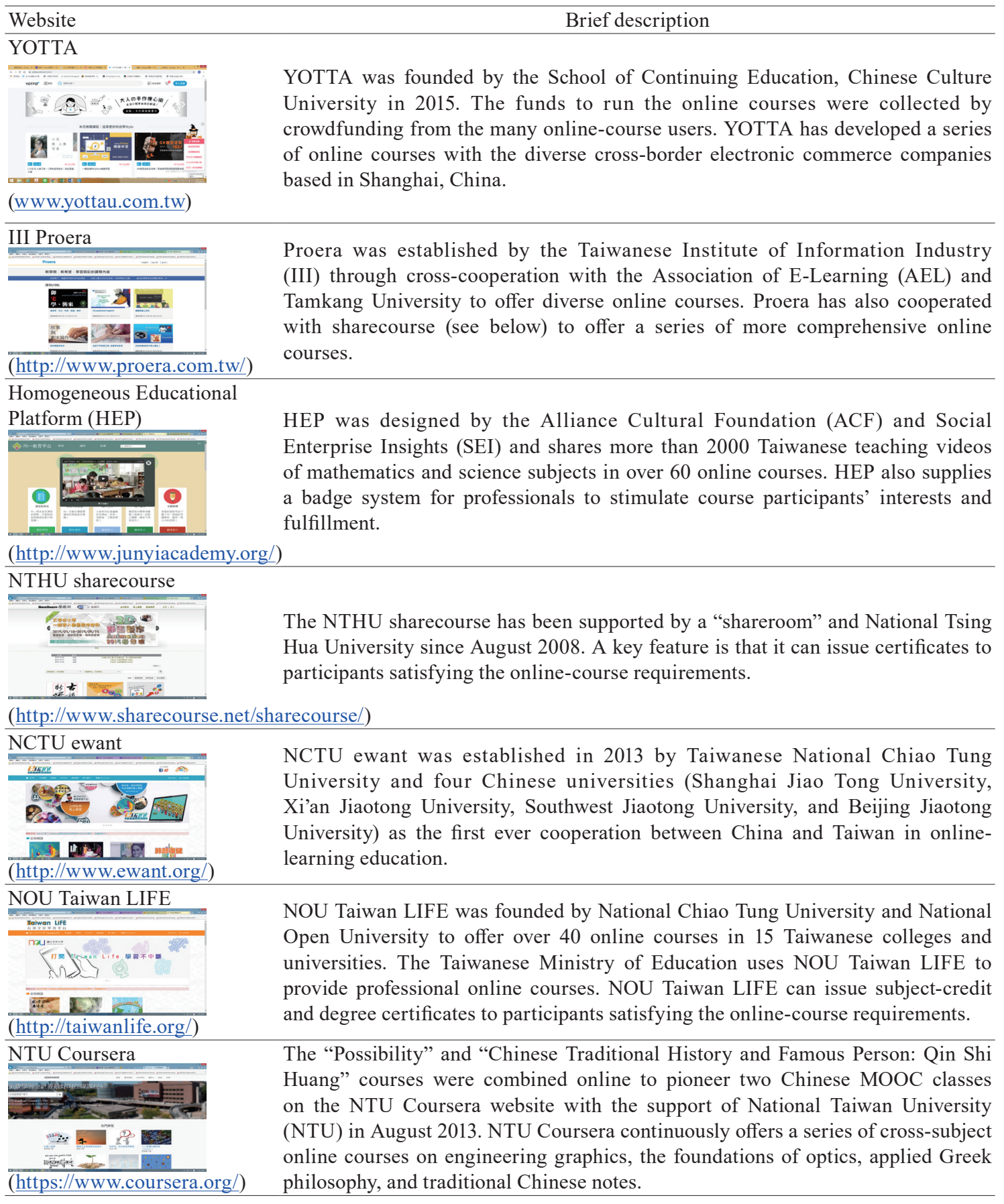

self-regulation learning performance, improve the evaluation system of educational institutions, and promote corporate recognition and identification, the use of sensor technologies in online courses in the post-COVID-19 era has been a major area of research across all forms of Taiwanese educational institutions, including senior high schools, vocational schools, colleges and universities, and adult continuous educational institutions. 
However, despite comprehensive related research, ${ }^{(3-5)}$ there has been no direct and extensive analysis or survey of the interactive relations among the self-regulated learning performance of students, ${ }^{(6)}$ the evaluation system of educational institutions, ${ }^{(7)}$ and corporate recognition and identification ${ }^{(8)}$ in the research results in the study of online courses. ${ }^{(9-11)}$ Significantly, the three factors of most critical importance for online courses are online-course learning performance, ${ }^{(12)}$ online-course evaluation authenticity, ${ }^{(13)}$ and online-course appraisal quality ${ }^{(14,15)}$ when considering the self-regulated learning performance of students, the evaluation system of educational institutions, and corporate recognition and identification. To explore the in-depth interplay among them, this study creatively employed social learning theory (SLT) ${ }^{(16)}$ to appraise online-course learning performance, online-course evaluation authenticity, and online-course appraisal quality on the basis of three core elements (students' individual cognition, educationinstitution group belongingness, and corporate social conditions) in the post-COVID-19 era. The most significant reasons for employing SLT are as follows: (1) each student's individual cognition comprises education-institution group belongingness, and education-institution group belongingness oppositely affects each student's individual cognition; (2) education-institution group belongingness constructs public social unity, and public social unity adversely impacts education-institution group belongingness, and (3) public social unity leads to each student's individual cognition, and each student's individual cognition directly affects the short-term development of public social unity as shown in Fig. 1. ${ }^{(17)}$

\section{Methodological Literature}

For the extensive analyses of online-course learning performance, online-course evaluation authenticity, and online-course appraisal quality, this study employed nine functional features of

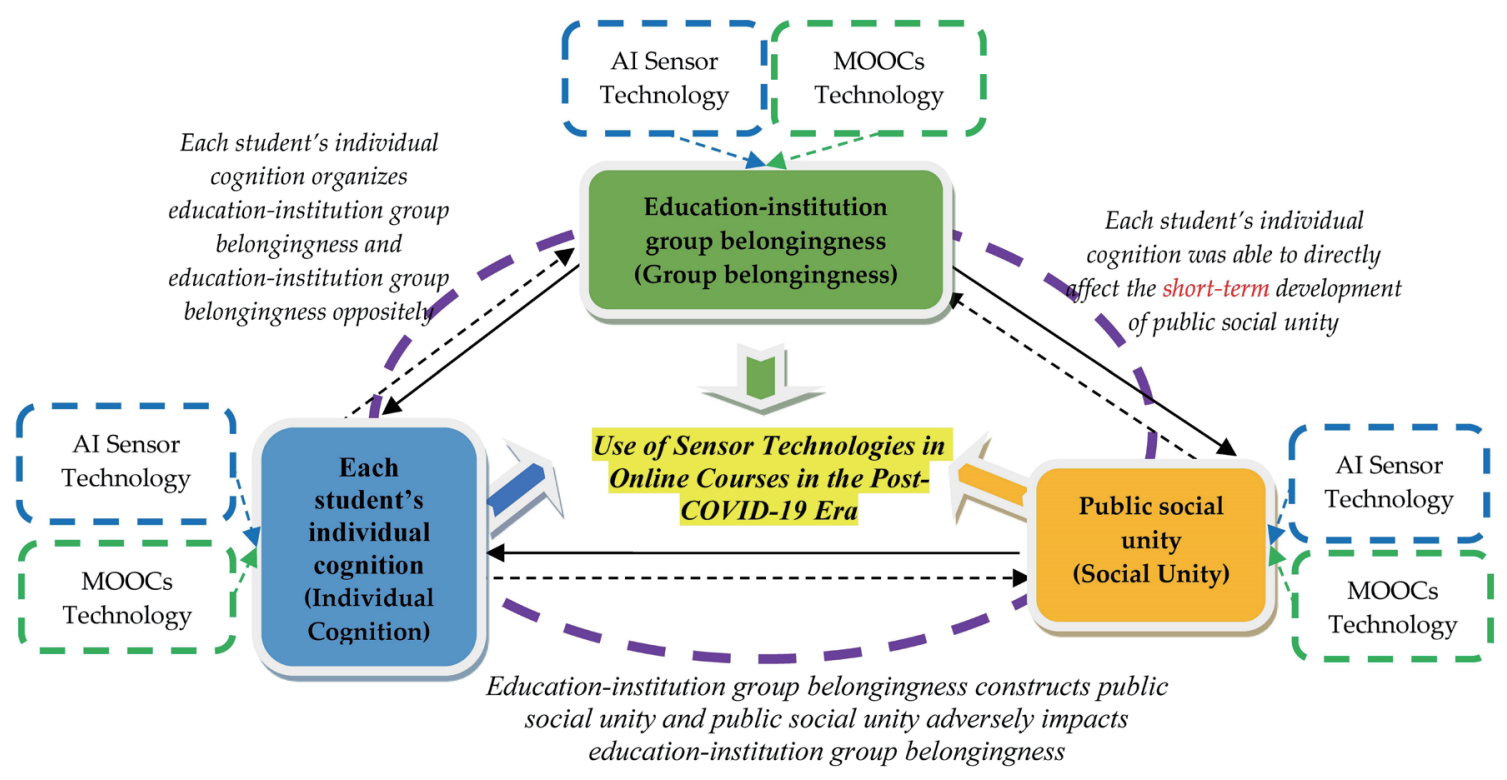

Fig. 1. (Color online) Main research analytical framework. 
sensor technology ${ }^{(18)}$ with 10 technological traits of MOOCs, ${ }^{(1)}$ which resulted from the authors' research findings. To comprehensively examine the research topic, not only the three brief analytical perspectives of SLT but also the factor analysis (FA) approach of quantitative analysis, the house of quality model of quality function deployment (HOQ-QFD) method, and the analytical network process (ANP) of the qualitative analysis of the multiple-criteria decisionmaking (MCDM) methodology ${ }^{(19-22)}$ have been cross-employed for the in-depth and extensive examination of the interactive dependences among the IoT technological traits of MOOCs and the functional features of sensor technology in this study.

\subsection{Research concepts}

For the fundamental research concepts of the self-regulated learning performance of students, the evaluation system of educational institutions, and corporate recognition and identification, this study employed nine functional features of sensor technology in an online class learning system from 10 technological traits of MOOCs based on the authors' research studies in MOOCrelated fields. ${ }^{(23)}$ The nine functional features of the sensor technology in a class learning system are as follows:(24) (1) audio sensor (AS): a sensor that can convert sound to electrical signals, (2) inertial sensor (IS): a sensor that detects the motion or rotation of an object without external references, such as an accelerometer measuring the specific force and a gyroscope measuring the angular rate, (3) individual identification sensor (IIS): a sensor that can identify a specific signal sender, (4) image sensor (ImS) (camera): a sensor that can detect and refer to data that constitute an image (e.g., pixels, colors, size), (5) environment sensor (chemosensor) (ES): a sensor used to detect certain chemical stimuli in the environment, (6) motion sensor (MS): a sensor that can detect moving objects, (7) scanning rangefinder (SR): a sensor that uses light to locate objects within a space,(8) biophysical sensor (BS): an electronic sensor that can take biological measurements from a human body, and (9) software sensor (SS): a sensor that provides data without depending on hardware devices, such as Logical Sensors (Windows), in which events can be monitored by answering questions with Yes or No (0 or 1) or by the use of text sensors, which use software to extract emotions from words and phrases. In succession, the 10 IoT technological traits of MOOCs were refined from the authors' accumulated research studies $^{(9-15)}$ and were defined as the user's completely unrestricted operation (UCUO), convenience $(\mathrm{C})$, connectionization $(\mathrm{CZ})$, openness $(\mathrm{O})$, course completion rate $(\mathrm{CCR})$, feedback technology function (FTF), course evaluation technology function (CETF), aggregation technology function (ATF), course professionalization technology function (CPTF), and repurposing technology function (RTF). ${ }^{(1)}$

\subsection{Research on measurement models and methods}

In the past, the decision-making selection methodology focused on calculating the maximum value of positively evaluated criteria or the minimum value of negatively appraised criteria for single measured standard numbers to find the best solution for research issues. However, in terms of the diversity and complexity of social evolution, the best solution cannot satisfy various 
current interdisciplinary research issues. As a result, the MCDM methodology was created by integrating a series of qualitative and quantitative methods to examine, analyze, and deal with the many complex research problems and decision-making selections by systematically instituting the most appropriate evaluation model of a new structural decision-making methodology. The core concepts of the MCDM methodology are to measure the optimal and suboptimal orders of each evaluated criterion to implement the best solutions for complex research problems or issues because complex research issues require the consideration of diverse analytical criteria based on the advantages and disadvantages of the MCDM methodology. However, there are usually conflicts between these diverse criteria. The MCDM methodology can be used to directly evaluate conflicting or nonconflicting appraised criteria to not only detect and interactively measure the optimal and suboptimal orders of each solution ${ }^{(25,26)}$ but also consider and measure the characteristics and attitudes of the conflicting or nonconflicting appraised criteria.

Beyond giving a comprehensive overview in Table 2, in this research, we cross-employed the FA method of quantitative analysis to analyze the results from a large-scale questionnaire of online-course users to increase research representativeness and validity. The QFD-HOQ method and the ANP model of qualitative analysis were also employed to evaluate the questionnaire data from professional experts for the purpose of strengthening the reliability and accuracy of research, as well as the factor analysis (FA) measure of qualitative analysis to reduce the linguistic amphiboly of questionnaires in the QFD-HOQ method of qualitative analysis and to increase the validity of the research. Specifically, in terms of the analyzed methodologies, this research employed the FA approach of quantitative analysis to complete an in-depth evaluation of the large-scale questionnaire data from online-course users to directly increase the representativeness of research. In view of the theoretical development of the FA approach, the variable communality of the correlation coefficient among each analytical variable is able to be systematically testified in the FA approach. To deal with more complex and philosophical research studies from the 1900s, the FA approach was developed as a more complex analysis method using the following complicated linear combination equation: ${ }^{(27)}$

Table 2

Descriptive statistics of questionnaire results.

\begin{tabular}{|c|c|c|c|c|c|}
\hline Gender & Male: 4 & $44(59.46 \%)$ & & Female: 30 (40. & $0.54 \%)$ \\
\hline Geography & $\begin{array}{c}\text { Northern Taiwan }{ }^{1} \text { : } \\
23(31.08 \%)\end{array}$ & $\begin{array}{r}\text { Central Te } \\
21(28.7\end{array}$ & $\begin{array}{r}\text { Southe } \\
22\end{array}$ & $\begin{array}{l}\text { rn Taiwan }{ }^{3}: \quad \text { Ea } \\
29.73 \%)\end{array}$ & $\begin{array}{c}\text { Eastern Taiwan }{ }^{4} \text { : } \\
8(10.41 \%)\end{array}$ \\
\hline $\begin{array}{l}\text { Use of Internet } \\
\text { hours/per day }\end{array}$ & $\begin{array}{c}\text { One hour and } \\
\text { below: } 8(10.81 \%)\end{array}$ & $\begin{array}{c}\text { Two hours: } 28 \\
(37.84 \%)\end{array}$ & $\begin{array}{c}\text { Three hours: } 24 \\
(32.42 \%)\end{array}$ & $\begin{array}{c}\text { Four hours: } 8 \\
(10.81 \%)\end{array}$ & $\begin{array}{c}\text { Over four hours: } \\
6(8.12 \%)\end{array}$ \\
\hline $\begin{array}{l}\text { Have you even } t \\
\text { educational inst }\end{array}$ & $\begin{array}{l}\text { n online course from } \\
\text { ?? }\end{array}$ & the website of & official & Yes: $21(28.38 \%)$ & No: $53(71.62 \%)$ \\
\hline Have you ever $\mathrm{t}$ & in online course for ar & ny educational c & gree? & Yes: $2(2.7 \%)$ & No: $72(97.3 \%)$ \\
\hline Have you ever $\mathrm{t}$ & n online course for ar & ny professional & ertification? & Yes: $18(24.32 \%)$ & No: $56(75.68 \%)$ \\
\hline
\end{tabular}




$$
\begin{aligned}
x_{j} & =u_{j}+\lambda_{j 1}+\lambda_{j 2} f_{1}+\ldots+\lambda_{j k} f_{m}+u_{j} \\
& =u_{j}+\lambda_{j 1}+\lambda_{j 2} f_{1}+\ldots+\lambda_{j k} f_{m}+s_{j}+e_{j} \\
j & =1, \ldots \ldots, p
\end{aligned}
$$

The factor loading is described as $\lambda_{j k}$ which means the numbers of variables $(j)$ in factor $(k)$ and specifically, $\lambda_{j k}$ is able to directly expresses the relationships between variables $(j)$ in factor $(k)$. $S_{j}$ is the number of factor loading of specific factor $(S)$ and $e_{j}$ is the number of analytic measurement errors. This equation represents the factor loading in FA and the average weights of overall influencing factors.

Specifically, in terms of the analyzed methodologies, this research employed the QFD-HOQ method to perform an in-depth analysis of the questionnaire results from surveyed professionals for the purpose of strengthening the reliability and accuracy of research. ${ }^{(28)}$ These experts comprised online-course lecturers, scholars, and researchers because the QFD-HOQ method effectively and instantaneously integrates experts' hyperchangeable desires on the online-course sensor technology in the evaluation model. The foundational characteristics and definitions of each utility in the QFD-HOQ method of qualitative analysis were expressed as follows:

1. Evaluated Unit: the analytical online courses with sensor technology were defined as the comprehensive research objective.

2. Online-course Lecturers, Users, Scholars, and Researchers: the surveyed online-course lecturers, users, scholars, and researchers were identified, and the objectives surveyed in the research were presented.

3. Demands of Online-course Lecturers, Users, Scholars, and Researchers (WHATs): the demands of the surveyed online-course lecturers, users, scholars, and researchers were represented as the requirements and expectations of online-course lecturers, users, scholars, and researchers through weight measurements based on completed questionnaires.

4. Correlation Matrix of WHATs: the correlation matrix of WHATs included the interplays in comparative pairwise measurements of each WHAT to refine and identify the most critical criteria of WHATs. To concretely describe the questionnaire results, Likert's scale was directly applied in the comparative pairwise measurements in association with the related interdependence and importance from equal importance to extreme importance for each question in the survey.

5. Relative Importance Ratings of WHATs: the related importance ratings of WHATs were assessed by the surveyed experts by questionnaire evaluation using Likert's scale.

6. Balance Point: the possibility of a good business position at a company to earn a high salary. Usually, the most important WHAT was rated "great", which, in turn, is defined as a "strong" balance point. A "moderate" balance point presents importance ratings (or competitive opportunity) that are balanced, and no importance was expressed as a "no" balance point.

7. Final Importance Ratings of WHATs: the final importance ratings of WHATs were computed as

Final related important ratings of WHATs

$=\sum$ (relative importance $\times$ ameliorating ratios $\times$ balance - point $)$ 
8. Competitors' Assessment: an assessment of the competitors' related products was appraised by the surveyed experts by comparing online-course sensor technology from a competitor's aspect and, specifically, the measured scale was similar to the importance ratings of WHATs.

9. Technical Competitive Assessment: the competitors' techniques were assessed to evaluate the performance of online-course sensor technology by comparing competitors' online-course sensor technology through pairwise comparisons of each HOW.

10. Online-course Sensor Technology Providers (HOWs): the comparative measurements of the online-course sensor technology requirements for experts related with the specifications of online-course sensor technology were directly interrelated with the WHATs.

11. Correlation Matrix of Technical Measurements: the correlation matrix not only covers the interplays between pairwise compared HOWs by comparing analysis and empirical experience but also provides evaluation measures to define and identify the trend of onlinecourse sensor technology to obtain sufficient competitiveness to compete with competitors using the evaluated scale of the correlation matrix of WHATs.

12. Goals for WHATs: the goals for WHATs were illustrated from the surveyed experts to achieve the demands of online-course lecturers, users, scholars, and researchers using the assessed scale of related importance ratings of WHATs.

13. Goals for HOWs: the goals for HOWs were established to measure the performance goals of each HOW to compete with competitors.

14. Related Importance Ratings of HOWs: the related importance ratings of HOWs for interviewed experts were evaluated by the interviewed experts and, specifically, the measured equation function of the related importance ratings of HOWs was expressed as

Related important ratings of the HOWs

$=\sum($ final importance rating of WHATs $\times$ relationship value between the WHATs and HOWs $)$

15. Reforming Directions of HOWs: the satisfaction of the interviewed online-course lecturers, users, and scholars was directly evaluated through ameliorating the directions of HOWs after measuring satisfaction by the QFD-HOQ method. Theoretically, there are different types of ameliorating directions: maximizing (or positively increasing) goals, satisfying goals (or guidelines, standards, and so on), and minimizing (or negatively decreasing) goals.

16. Relationship Matrix between each WHAT and HOW: the pairwise matrix of relationships between WHATs and HOWs was able to distinguish the correlated level between each WHAT and HOW by questionnaire evaluation using Likert's scale.

17. Refined Probable Factors: the refined probable factors were able to satisfy the goals for each HOW by questionnaire evaluation with Likert's scale.

Subsequently, in light of the brief description of the concept of the QFD-HOQ method, the interrelationship between all WHATs and HOWs was systematically evaluated and hierarchically analyzed by means of the relationship matrix (WHATs vs HOWs) and technological requirement matrix (HOWs vs WHATs) to distinctly identify the optimal and suboptimal orders of the best solution and non-inferior solutions of WHATs and HOWs (HOW goal matches). After defining each indispensable element in the QFD-HOQ method, the statistically measured calculations 
were comprehensively considered and established step-by-step to apply each appraisal metric: the WHATs, the related importance ratings of WHATs, the HOWs, the related importance ratings of HOWs, and the relationship matrix between WHATs and HOWs. To fully verify the analytical results, the ANP model was further applied to classify the weights of WHATs and HOWs in the QFD-HOQ method.

In response to the increasing complexity of research topics, ${ }^{(29)}$ the ANP approach was created to appraise each factor through evaluated hierarchies of the patterns, criteria (factors), subcriteria, and selected candidates by a pairwise matrix to deal with experts' questionnaire results through the Delphi method and a brainstorm approach in a comprehensive, limitedresource, and difficult-decision environment. To perform an in-depth and extensive analysis of the interaction relations between each factor, ${ }^{(30-33)}$ the ANP model was created to discuss the consistency of each factor through the measurement of the consistency index (C.I.), consistency ratio (C.R.), and random inconsistency (R.I.) of the entire matrix of pairwise comparisons between the patterns, criteria (factors), subcriteria, and selected candidates. The two-stage algorithms of C.I., C.R., and R.I. in the ANP model are expressed as

$$
\text { C.I. }=\left(\lambda_{\max }-n\right) /(n-1) ; \text { C.R. }=\text { C.I. } / \text { R.I. }
$$

Significantly, in association with the assessed consistency of the research validity, all the C.R values in the matrix of pairwise comparisons have to be lower than 0.1 .

\section{Research Design}

\subsection{Survey process}

To concretely impose the research structure, the following four primary steps of the research processes are systematically administered as shown in Fig. 2. (1) First procedure: Concrete construction of MCDM methodology. (2) Second procedure: Practical experiments on MCDM methodology. (3) Third procedure: Verify MCDM methodology. (4) Fourth procedure: Compare experimental results with academic results.

\subsection{Surveyed interviewees}

To increase the representativeness and validity of research in the FA approach of quantitative analysis and improve the reliability and accuracy of research in the QFD-HOQ method and the ANP model of qualitative analysis, 150 online-course users were interviewed using the FA approach, 10 professional experts were interviewed using the QFD-HOQ method, and 15 experts of digital education and sensor technology were further scrutinized using the ANP model to validate the data results of the QFD-HOQ method. The 10 professional experts include five scholars with over 5 years of research experience in sensor technology research and related fields and five other professionals with over 5 years of working experience in the online-course industry. The 15 experts comprise five professors with a primary focus on online learning in the 
First procedure: Concrete construction of MCDM methodology

- Comprehensively analyze the interdependences among the self-regulated learning performance of students, the evaluation system of educational institutions, and corporate recognition and identification.

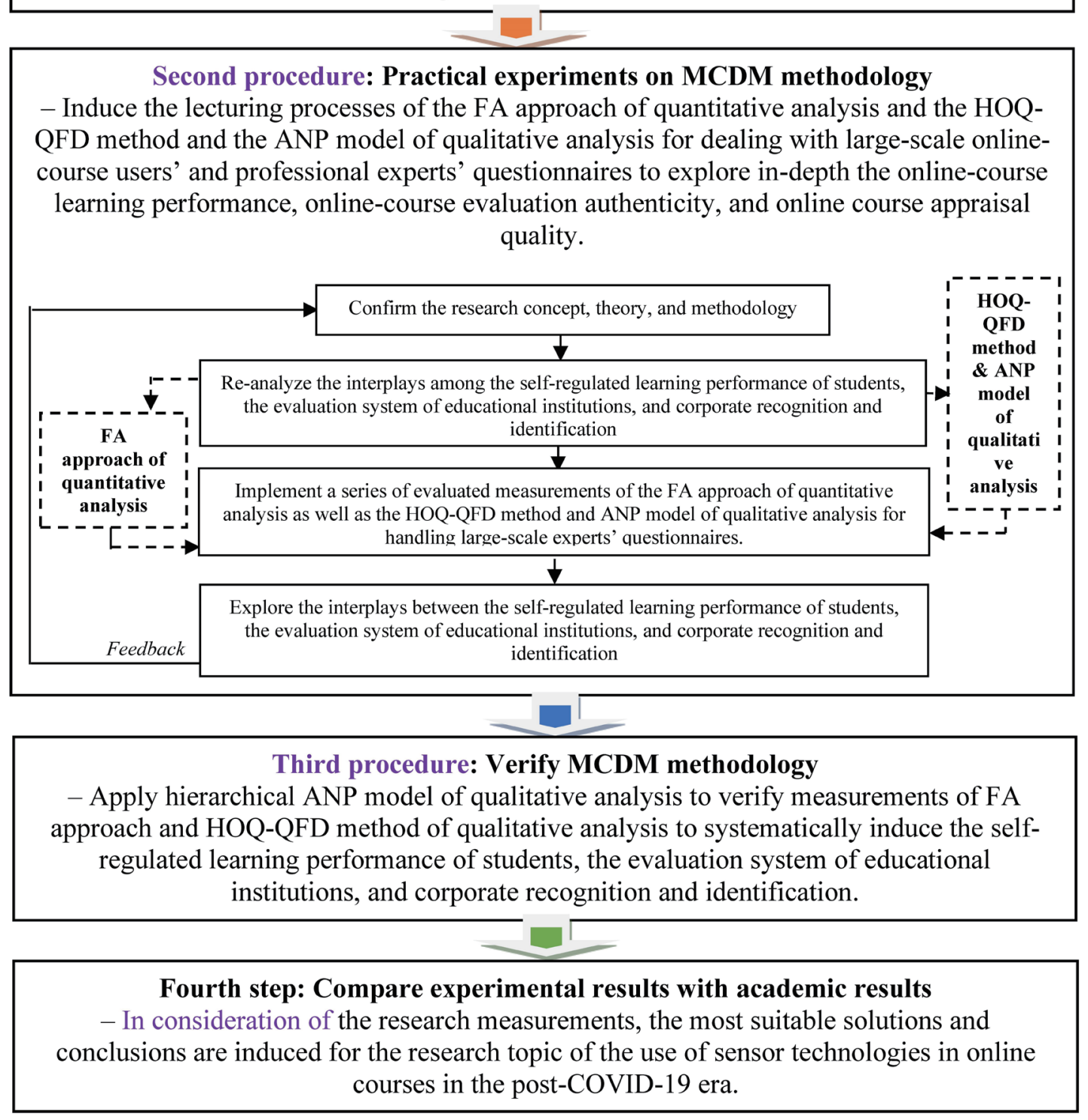

Fig. 2. (Color online) Four primary administered steps of the research process.

past 5 years, five online-course practitioners with over 5 years of work experience in related online industries, and five specialists who have over 5 years of experience in online-course design and evaluation. 


\section{Evaluated Measurements}

To comprehensively improve the reliability, validity, and accuracy of research, the qualitative and quantitative analyses of MCDM methodology were cross-applied to the QFD-HOQ method. The research measurements were systematically administered as follows:

First Step: Defining the WHATs to identify overall priorities compared with the HOWs by pairwise comparisons. In terms of the appraised measurements, the following 10 technological traits of MOOCs from the authors' research findings were defined as the WHATs: UCUO $\left(W_{1}\right)$, $\mathrm{C}\left(W_{2}\right), \mathrm{CZ}\left(W_{3}\right), \mathrm{O}\left(W_{4}\right), \mathrm{CCR}\left(W_{5}\right), \operatorname{FTF}\left(W_{6}\right), \operatorname{CETF}\left(W_{7}\right), \operatorname{ATF}\left(W_{8}\right), \operatorname{CPTF}\left(W_{9}\right)$, and RTF $\left(W_{10}\right)$. To enhance this research representativeness, the FA approach of quantitative analysis was first applied to deal with the questionnaires of 75 current online-course users, and, in detail, the FA approach of quantitative analysis was first applied to the population of 75 current onlinecourse users that received the questionnaire, of which 74 questionnaires were completed, giving a valid response of $98.67 \%$. The descriptive statistics of the 74 valid questionnaires are given in Table 2.

According to Eq. (1) based on the FA approach, the Kaiser-Meyer-Olkin measure of the sampling adequacy of the WHATs was 0.754 , which was higher than 0.7, and the assessed number of significance of the Kaiser-Meyer-Olkin measure and Bartlett test was 0.000 (Table 3), which was also lower than 0.05 . This means that the FA approach was employed to measure these 74 valid weight-questionnaires.

Table 4 shows the commonality of each assessed criterion using the FA approach and the numbers of commonality of each "WHAT".

The nine functional features of the sensor technology in a class learning system were defined as the HOWs and are AS $\left(H_{1}\right)$, IS $\left(H_{2}\right)$, IIS $\left(H_{3}\right), \operatorname{ImS}\left(H_{4}\right)$, ES $\left(H_{5}\right)$, MS $\left(H_{6}\right)$, SR $\left(H_{7}\right)$, BS $\left(H_{8}\right)$, and SS $\left(H_{9}\right)$. Then, the FA approach of quantitative analysis was also applied to handle the questionnaires of 75 current online-course users and, in detail, the FA approach of quantitative analysis was first applied to the population of 75 current online-course users that received the questionnaire, of which 74 questionnaires were completed, giving a valid response of $98.67 \%$. The descriptive statistics of the 74 valid questionnaires are given in Table 5.

Table 3

Kaiser-Meyer-Olkin measure and Bartlett's test in FA approach.

\begin{tabular}{llc}
\hline Kaiser-Meyer-Olkin & \\
measure of sampling adequacy & 0.754 \\
\hline $\begin{array}{l}\text { Bartlett test } \\
\text { of sphericity }\end{array}$ & Chi-squared test & 130.209 \\
\cline { 2 - 3 } & df & 45 \\
\hline
\end{tabular}

Table 4

Commonality of each WHAT criterion in FA approach.

\begin{tabular}{lcc}
\hline & Initial & Weight \\
\hline $\operatorname{UCUO}\left(W_{1}\right)$ & 1 & 0.67 \\
$\mathrm{C}\left(W_{2}\right)$ & 1 & 0.687 \\
$\mathrm{CZ}\left(W_{3}\right)$ & 1 & 0.705 \\
$\mathrm{O}\left(W_{4}\right)$ & 1 & 0.682 \\
$\operatorname{CCR}\left(W_{5}\right)$ & 1 & 0.713 \\
$\operatorname{FTF}\left(W_{6}\right)$ & 1 & 0.55 \\
$\operatorname{CETF}\left(W_{7}\right)$ & 1 & 0.601 \\
$\operatorname{ATF}\left(W_{8}\right)$ & 1 & 0.527 \\
$\operatorname{CPTF}\left(W_{9}\right)$ & 1 & 0.679 \\
$\operatorname{RTF}\left(W_{10}\right)$ & 1 & 0.777 \\
\hline
\end{tabular}


Table 5

Descriptive statistics of FA approach.

\begin{tabular}{|c|c|c|c|c|c|}
\hline Gender & Male: 3 & $36(48.65 \%)$ & & Female: 38 (51. & $1.35 \%)$ \\
\hline Geography & $\begin{array}{c}\text { Northern Taiwan }^{1} \text { : } \\
20(27.03 \%)\end{array}$ & $\begin{array}{r}\text { Central Te } \\
24(32 .\end{array}$ & $\begin{array}{c}\text { Southe } \\
21\end{array}$ & $\begin{array}{l}\text { rn Taiwan }{ }^{3}: \\
28.38 \%)\end{array}$ & $\begin{array}{c}\text { Eastern Taiwan }{ }^{4}: \\
9(12.16 \%)\end{array}$ \\
\hline $\begin{array}{l}\text { Use of Internet } \\
\text { hours/per day }\end{array}$ & $\begin{array}{c}\text { One hour and } \\
\text { below: } 12(16.22 \%)\end{array}$ & $\begin{array}{c}\text { Two hours: } 25 \\
(33.78 \%)\end{array}$ & $\begin{array}{c}\text { Three hours: } 23 \\
(31.08 \%)\end{array}$ & $\begin{array}{c}\text { Four hours: } 10 \\
(13.51 \%)\end{array}$ & $\begin{array}{c}\text { Over four hours: } \\
4(5.41 \%)\end{array}$ \\
\hline $\begin{array}{l}\text { Have you even } t \\
\text { educational inst }\end{array}$ & $\begin{array}{l}\text { an online course from } \\
\text { ? }\end{array}$ & the website of a & official & Yes: $13(17.57 \%))$ & No: $61(82.43 \%)$ \\
\hline Have you ever $\mathrm{t}$ & $n$ online course for an & y educational de & rree? & Yes: $3(4.05 \%)$ & No: $71(95.95 \%)$ \\
\hline Have you ever t & $n$ online course for an & $y$ professional c & rtification? & Yes: $12(16.22 \%)$ & No: $62(83.78 \%)$ \\
\hline
\end{tabular}

From the statistical equation of the FA approach, the Kaiser-Meyer-Olkin measure of the sampling adequacy of the WHATs was 0.731, which was higher than 0.7, and the assessed number of the significance of the Kaiser-Meyer-Olkin measure and Bartlett test was 0.000, which was also lower than 0.05 (Table 3). This means that the FA approach was employed to measure these 74 valid questionnaires as described in Table 6.

Table 7 shows the commonality of each assessed criterion in the FA approach and the numbers of commonality of the "WHATs" in Table 4.

Second Step: Administering the complete related importance ratings of WHATs (W1 matrix): To comprehensively reflect the extent of online-course users' desires, we collected the compare-matrix questionnaire weights from five experts who have focused on online-course design and content for over 5 years. Mainly, to avoid vagueness of the questionnaire, the ninepoint Likert's scale was utilized in the measurements of the complete related importance ratings of the 10 WHATs using Eqs. (2)-(4) as illustrated in Table 8.

Third Step: Analyzing competitors and conducting competitive analysis of entropy method in QFD-HOQ method: To increase the validity and accuracy of the research, the competitive analysis of each HOW was conducted in a series of calculations to analyze four major onlinecourse websites: III Proera $\left(\mathrm{C}_{\mathrm{A}}\right)$, Homogeneous Educational Platform (HEP) $\left(\mathrm{C}_{\mathrm{B}}\right)$, NTHU sharecourse $\left(\mathrm{C}_{\mathrm{C}}\right)$, and NTU Coursera $\left(\mathrm{C}_{\mathrm{D}}\right)$. In association with the compared equations of the QFD-HOQ method, the statistical entropy method was utilized in the measurement of the probability distribution to calculate a series of compared entropy numbers $\left(E M\left(H_{m}\right)\right)$ because the amounts of uncertainty and various databases were measured by a discrete probability distribution $\left(E M\left(H_{1}, H_{2}, \ldots, H_{m}\right)\right)$ using the following equation:

$$
E M\left(H_{1}, H_{2}, \ldots, H_{m}\right)=-\varnothing_{L} \sum_{l=1}^{L} \mathrm{P}_{l} \operatorname{In}\left(p_{l}\right),
$$

where $\varnothing_{L}=1 / \operatorname{In}(L)$ is a normalization constant to ensure that $0 \leq E M\left(H_{1}, H_{2}, \ldots, H_{m}\right) \leq 1$. 
Table 6

Kaiser-Meyer-Olkin measure and Bartlett's test in FA approach.

\begin{tabular}{llc}
\hline \multirow{2}{*}{$\begin{array}{l}\text { Kaiser-Meyer-Olkin measure } \\
\text { of sampling adequacy }\end{array}$} & 0.731 \\
\hline $\begin{array}{l}\text { Bartlett test } \\
\text { of sphericity }\end{array}$ & Chi-squared test & 108.653 \\
\cline { 2 - 3 } & Significance & 36 \\
\hline
\end{tabular}

Table 7

Commonality of each assessed criterion in FA approach.

\begin{tabular}{lcl}
\hline & Initial & Weights \\
\hline AS $\left(H_{1}\right)$ & 1 & 0.74 \\
IS $\left(H_{2}\right)$ & 1 & 0.725 \\
IIS $\left(H_{3}\right)$ & 1 & 0.793 \\
$\operatorname{ImS~}\left(H_{4}\right)$ & 1 & 0.689 \\
ES $\left(H_{5}\right)$ & 1 & 0.753 \\
MS $\left(H_{6}\right)$ & 1 & 0.742 \\
SR $\left(H_{7}\right)$ & 1 & 0.675 \\
BS $\left(H_{8}\right)$ & 1 & 0.589 \\
SS $\left(H_{9}\right)$ & 1 & 0.754 \\
\hline
\end{tabular}

Table 8

Commonality of each HOW criterion in HOQ-QFD method.

\begin{tabular}{lccccccc}
\hline & $\begin{array}{c}\text { FA approach } \\
\text { loading }\end{array}$ & Scholar 1 & Expert 2 & Expert 3 & Expert 4 & Expert 5 $\begin{array}{c}\text { Related importance } \\
\text { rating }\end{array}$ \\
\hline AS $\left(H_{1}\right)$ & 0.67 & 7 & 8 & 7 & 8 & 7 & 2.6122 \\
IS $\left(H_{2}\right)$ & 0.687 & 8 & 5 & 7 & 7 & 6 & 2.3298 \\
IIS $\left(H_{3}\right)$ & 0.705 & 6 & 7 & 6 & 8 & 5 & 2.2592 \\
ImS $\left(H_{4}\right)$ & 0.682 & 5 & 5 & 5 & 6 & 7 & 1.9768 \\
ES $\left(H_{5}\right)$ & 0.713 & 6 & 6 & 6 & 8 & 4 & 1.506 \\
MS $\left(H_{6}\right)$ & 0.55 & 6 & 6 & 8 & 6 & 6 & 1.6064 \\
SR $\left(H_{7}\right)$ & 0.601 & 6 & 5 & 6 & 6 & 6 & 1.4558 \\
BS $\left(H_{8}\right)$ & 0.527 & 5 & 5 & 8 & 5 & 7 & 1.506 \\
SS $\left(H_{9}\right)$ & 0.679 & 8 & 6 & 6 & 5 & 6 & 1.4756 \\
AS $\left(H_{1}\right)$ & 0.777 & 7 & 5 & 5 & 7 & 7 & 1.4756 \\
\hline
\end{tabular}

For row $m$ of the comparison matrix $X$ from five professionals corresponding to the HOWs $D_{m}$, the total measured weights with reference to $E M\left(H_{1}, H_{2}, \ldots, H_{m}\right)$ can be computed as $X_{m}=\sum_{l=1}^{L} ; X=\left(X_{1}, X_{2}, \ldots, X_{m}\right)$. To fully detect the impact of sensor technology used by the four appraised competitors for the nine HOWs, Eq. (5) was expanded as

$$
\begin{aligned}
\operatorname{EM}\left(H_{1}, H_{2}, \ldots ., H_{m}\right) & =E M\left(H O W s_{m}\right) \\
& =-\varnothing_{L} \sum_{l=1}^{L} P_{m L} \operatorname{In}\left(p_{m L}\right) \\
& =-\varnothing_{L} \sum_{l=1}^{L}\left(X_{m L} / X_{m}\right) \operatorname{In}\left(X_{m L} / X_{m}\right)
\end{aligned}
$$

and used to measure the probability distribution $\operatorname{EM}\left(H_{1}, H_{2}, \ldots, H_{m}\right)$ as shown in Table 9 .

Fourth Step: Implementing the experts' weighted matrix of the hierarchical ANP model. This fourth step is completed to more effectively and efficiently reinforce the credibility and accuracy of research, and the weighted questionnaire results of 15 experts are further analyzed in the hierarchical model from three perspectives: online-course learning performance, onlinecourse evaluation authenticity, and online-course appraisal quality. The analytical research hierarchy of the ANP model is constructed in Fig. 3. 
Table 9

Commonality of each HOW criterion in QFD-HOQ method.

\begin{tabular}{|c|c|c|c|c|c|c|c|c|c|c|c|c|c|c|c|c|c|c|c|c|c|c|c|c|c|c|}
\hline & \multicolumn{4}{|c|}{ Professional 1} & \multicolumn{4}{|c|}{ Professional 2} & \multicolumn{4}{|c|}{ Professional 3} & \multicolumn{4}{|c|}{ Professional 4} & \multicolumn{4}{|c|}{ Professional 5} & \multicolumn{4}{|c|}{$\begin{array}{c}\text { Competitive } \\
\text { Analysis }\end{array}$} & \multirow[t]{2}{*}{$I R_{x}$} & \multirow[t]{2}{*}{$E M$} \\
\hline & $\overline{C_{A}}$ & $C_{B}$ & $C_{C}$ & $C_{D}$ & $C_{A}$ & $C_{B}$ & $C_{C}$ & $C_{D}$ & $C_{A}$ & $C_{B}$ & $C_{C}$ & $C_{D}$ & $C_{A}$ & $C_{B}$ & $C_{C} C$ & $C_{D}$ & $C_{A} C$ & $C_{B} C$ & $C_{C} C$ & $C_{D} \quad$ & $C_{A}$ & $C_{B}$ & $C_{C}$ & $C_{D}$ & & \\
\hline$\overline{\mathrm{AS}}\left(H_{1}\right)$ & 8 & 6 & 7 & 6 & 5 & 4 & 5 & 5 & 4 & 4 & 6 & 5 & 4 & 5 & 5 & 7 & 7 & 5 & 5 & 66 & 6.4 & 6.8 & 5.8 & 5.8 & 1.4286 & 0.1111 \\
\hline IS $\left(H_{2}\right)$ & 7 & 4 & 6 & 8 & 5 & 4 & 8 & 6 & 8 & 5 & 4 & 8 & 5 & 6 & 5 & 5 & 7 & 4 & 8 & 8 & 6.8 & 6.4 & 5.2 & 6.6 & 1.25 & 0.1109 \\
\hline IIS $\left(H_{3}\right)$ & 5 & 6 & 4 & 5 & 5 & 6 & 5 & 5 & 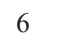 & 8 & 5 & 7 & 5 & 5 & 6 & 6 & 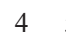 & 5 & 6 & 6 & 6.8 & 6 & 5.4 & 6 & 1.6 & 0.1113 \\
\hline $\operatorname{ImS}\left(H_{4}\right)$ & 5 & 5 & 5 & 5 & 5 & 5 & 8 & 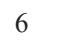 & 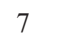 & 6 & 8 & 5 & 6 & $J$ & 5 & 7 & & 8 & 7 & 4 & 4.4 & 5.6 & 5.8 & 5.2 & 1.4286 & 1115 \\
\hline $\operatorname{ES}\left(H_{5}\right)$ & 4 & 8 & 5 & 4 & 4 & 8 & 6 & 3 & 8 & 7 & 6 & 6 & 5 & 4 & 8 & 3 & 8 & 5 & 8 & $8 \quad 5$ & 5 & 5.6 & 5.4 & 5 & 1.3793 & 0.1114 \\
\hline $\operatorname{MS}\left(H_{6}\right)$ & 5 & 6 & 6 & 5 & 5 & 6 & 7 & 5 & 6 & 8 & 7 & 7 & 4 & 5 & 6 & 5 & 5 & 6 & 7 & $6 \quad 5$ & 5.8 & 6.2 & 5.8 & 6 & 1.6 & 0.111 \\
\hline $\operatorname{SR}\left(H_{7}\right)$ & 8 & 7 & 5 & 5 & 8 & 7 & 8 & 3 & 5 & 4 & 8 & 3 & 3 & 8 & 7 & 8 & 6 & 7 & 6 & $\begin{array}{ll}8 & 4\end{array}$ & 4.8 & 5.8 & 6.2 & 5.2 & 1.3333 & 0.1118 \\
\hline $\mathrm{BS}\left(H_{8}\right)$ & 5 & 8 & 6 & 3 & 5 & 8 & 6 & 5 & 6 & 5 & 6 & 5 & 6 & 5 & 8 & 7 & 5 & 4 & 5 & 65 & 5.2 & 4.6 & 5.6 & 5.2 & 1.4815 & 0.1114 \\
\hline $\mathrm{SS}\left(H_{9}\right)$ & 2 & 5 & 8 & 5 & 6 & 4 & 5 & 7 & 8 & 3 & 5 & 4 & 5 & 6 & 6 & 4 & 4 & 3 & 8 & $\begin{array}{ll}7 & 5\end{array}$ & 5 & 4.2 & 5.8 & 4.6 & 1.6 & 0.1096 \\
\hline
\end{tabular}

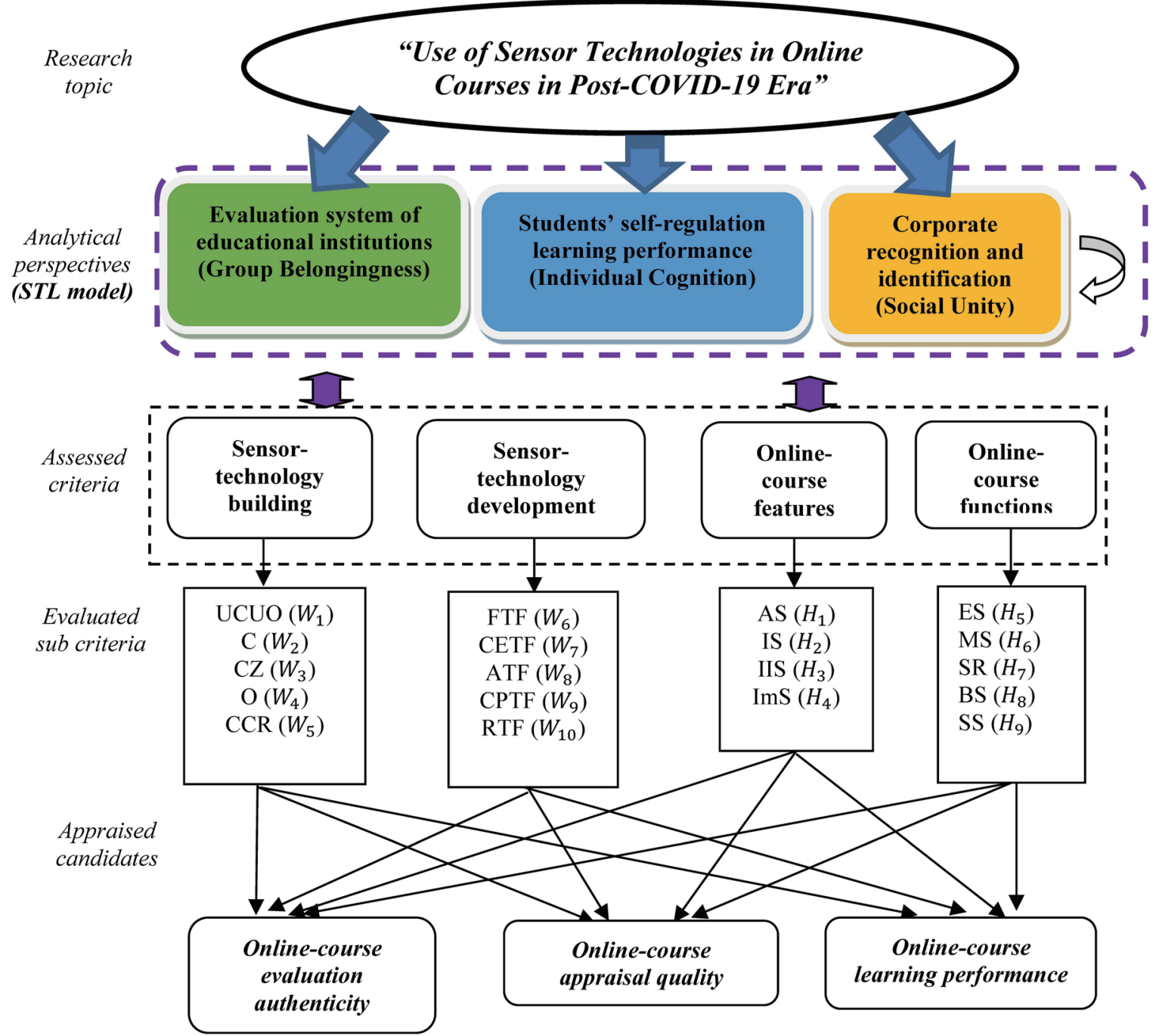

Fig. 3. (Color online) Four primary administered steps of the research processes. 
Subsequently, in association with statistically measured principles of the ANP model, the C.I. and C.R. of each analytical perspective, appraised criterion, and evaluated subcriterion were smaller than 0.1, as shown in Table 10, which means that the consistency of the entire ANP model pairwise matrix was accepted with high measured conformity and validity.

The most significant weighted measurements were the standardized comprehensive comparative indicators (SCCIs) of the online-course evaluation authenticity, online-course appraisal quality, and online-course learning performance, which were found to be 0.0696, 0.2559 , and 0.6745 , respectively, by consolidating a series of surveyed weights of the FA approach, HOQ-QFD method, and ANP model from three analytical perspectives of the STL model. Specifically, the three highest evaluated scores of the WHATs were RTF $\left(W_{10}\right)(0.0622)$, CPTF $\left(W_{9}\right)(0.0544)$, and CETF $\left(W_{7}\right)(0.0476)$, and the three highest evaluated scores of the HOWs were SS $\left(H_{9}\right)(0.039)$, MS $\left(H_{6}\right)(0.039)$, and ES $\left(H_{5}\right)(0.0389)$ as shown in Table 11.

Table 10

C.I. and C.R. of each analytical perspective, appraised criterion, and evaluated subcriterion in ANP model pairwise matrix.

\begin{tabular}{lll}
\hline Analytical perspective, appraised criterion, and evaluated subcriterion & C.I. & C.R. \\
\hline Evaluation system of educational institutions (group belongingness) & 0.0794 & 0.0881 \\
\hline Students' self-regulation learning performance (individual cognition) & 0.0695 & 0.0882 \\
\hline Corporate recognition and identification (social unity) & 0.0715 & 0.0795 \\
\hline Sensor-technology building & 0.0459 & 0.0792 \\
\hline Sensor-technology development & 0.0469 & 0.0808 \\
\hline Online-course features & 0.0549 & 0.0947 \\
\hline Online-course functions & 0.0502 & 0.0865 \\
\hline UCUO $\left(W_{1}\right)$ & 0.049 & 0.0845 \\
\hline C $\left(W_{2}\right)$ & 0.0407 & 0.0701 \\
\hline CZ $\left(W_{3}\right)$ & 0.0495 & 0.0853 \\
\hline O $\left(W_{4}\right)$ & 0.0419 & 0.0723 \\
\hline CCR $\left(W_{5}\right)$ & 0.0289 & 0.0498 \\
\hline FTF $\left(W_{6}\right)$ & 0.0438 & 0.0754 \\
\hline AETF $\left(W_{7}\right)$ & 0.0549 & 0.0947 \\
\hline CPTF $\left(W_{8}\right)$ & 0.0539 & 0.093 \\
\hline RTF $\left(W_{10}\right)$ & 0.0468 & 0.0807 \\
\hline AS $\left(H_{1}\right)$ & 0.0439 & 0.0757 \\
\hline IS $\left(H_{2}\right)$ & 0.0527 & 0.0909 \\
\hline IIS $\left(H_{3}\right)$ & 0.0395 & 0.0682 \\
\hline ImS $\left(H_{4}\right)$ & 0.0459 & 0.0791 \\
\hline ES $\left(H_{5}\right)$ & 0.0503 & 0.0868 \\
\hline MS $\left(H_{6}\right)$ & 0.0481 & 0.0829 \\
\hline SR $\left(H_{7}\right)$ & 0.0428 & 0.0738 \\
\hline SS $\left(H_{8}\right)$ & 0.0484 & 0.0834 \\
\hline
\end{tabular}


Table 11

SCCI measurements of ANP model.

\begin{tabular}{|c|c|c|c|c|c|c|c|c|c|}
\hline \multirow[b]{2}{*}{ Criterion } & \multirow[b]{2}{*}{ Subcriterion } & \multirow[b]{2}{*}{$\begin{array}{c}\text { FA } \\
\text { weight }\end{array}$} & \multirow[b]{2}{*}{$\begin{array}{l}\text { QFD-HOQ } \\
\text { weight }\end{array}$} & \multicolumn{2}{|c|}{$\begin{array}{c}\text { Online-course } \\
\text { evaluation } \\
\text { authenticity }\end{array}$} & \multicolumn{2}{|c|}{$\begin{array}{l}\text { Online-course } \\
\text { appraisal quality }\end{array}$} & \multicolumn{2}{|c|}{$\begin{array}{c}\text { Online-course } \\
\text { learning performance }\end{array}$} \\
\hline & & & & Weight & $\begin{array}{c}\text { Evaluated } \\
\text { score }\end{array}$ & Weight & $\begin{array}{c}\text { Evaluated } \\
\text { score }\end{array}$ & Weight & $\begin{array}{c}\text { Evaluated } \\
\text { score }\end{array}$ \\
\hline \multirow{5}{*}{$\begin{array}{l}\text { Sensor- } \\
\text { technology } \\
\text { building } \\
(0.0282)\end{array}$} & UCUO $\left(W_{1}\right)$ & 0.67 & 2.6122 & 0.0593 & 0.0029 & 0.2077 & 0.0103 & 0.733 & 0.0362 \\
\hline & $\mathrm{C}\left(W_{2}\right)$ & 0.687 & 2.3298 & 0.0555 & 0.0025 & 0.1975 & 0.0089 & 0.7471 & 0.0337 \\
\hline & $\mathrm{CZ}\left(W_{3}\right)$ & 0.705 & 2.2592 & 0.059 & 0.0027 & 0.2139 & 0.0096 & 0.7271 & 0.0327 \\
\hline & $\mathrm{O}\left(W_{4}\right)$ & 0.682 & 1.9768 & 0.0659 & 0.0025 & 0.2229 & 0.0085 & 0.7112 & 0.0271 \\
\hline & $\operatorname{CCR}\left(W_{5}\right)$ & 0.713 & 1.506 & 0.0594 & 0.0018 & 0.2256 & 0.0068 & 0.715 & 0.0217 \\
\hline \multirow{5}{*}{$\begin{array}{l}\text { Sensor- } \\
\text { technology } \\
\text { development } \\
(0.0747)\end{array}$} & $\operatorname{FTF}\left(W_{6}\right)$ & 0.55 & 1.6064 & 0.0575 & 0.0038 & 0.2238 & 0.0148 & 0.7187 & 0.0474 \\
\hline & $\operatorname{CETF}\left(W_{7}\right)$ & 0.601 & 1.4558 & 0.0574 & 0.0037 & 0.2145 & 0.014 & 0.7281 & 0.0476 \\
\hline & $\operatorname{ATF}\left(W_{8}\right)$ & 0.527 & 1.506 & 0.0604 & 0.0036 & 0.2201 & 0.013 & 0.7194 & 0.0426 \\
\hline & $\operatorname{CPTF}\left(W_{9}\right)$ & 0.679 & 1.4756 & 0.0599 & 0.0045 & 0.2128 & 0.0159 & 0.7273 & 0.0544 \\
\hline & $\operatorname{RTF}\left(W_{10}\right)$ & 0.777 & 1.4756 & 0.0599 & 0.0051 & 0.2128 & 0.0182 & 0.7273 & 0.0622 \\
\hline \multirow{4}{*}{$\begin{array}{l}\text { Online- } \\
\text { course } \\
\text { features } \\
(0.2455)\end{array}$} & $\mathrm{AS}\left(H_{1}\right)$ & 0.74 & 0.1111 & 0.0588 & 0.0012 & 0.2187 & 0.0044 & 0.7225 & 0.0146 \\
\hline & IS $\left(H_{2}\right)$ & 0.725 & 0.1109 & 0.0566 & 0.0011 & 0.2187 & 0.0043 & 0.2187 & 0.0043 \\
\hline & IIS $\left(H_{3}\right)$ & 0.793 & 0.1113 & 0.057 & 0.0012 & 0.2179 & 0.0047 & 0.7252 & 0.0157 \\
\hline & $\operatorname{ImS}\left(H_{4}\right)$ & 0.689 & 0.1115 & 0.061 & 0.0012 & 0.2217 & 0.0042 & 0.7173 & 0.0135 \\
\hline \multirow{5}{*}{$\begin{array}{l}\text { Online- } \\
\text { course } \\
\text { functions } \\
(0.6516)\end{array}$} & $\mathrm{ES}\left(H_{5}\right)$ & 0.753 & 0.1114 & 0.0616 & 0.0034 & 0.2277 & 0.0124 & 0.7108 & 0.0389 \\
\hline & $\operatorname{MS}\left(H_{6}\right)$ & 0.742 & 0.111 & 0.0583 & 0.0031 & 0.2149 & 0.0115 & 0.7268 & 0.039 \\
\hline & $\operatorname{SR}\left(H_{7}\right)$ & 0.675 & 0.1118 & 0.0549 & 0.0027 & 0.2135 & 0.0105 & 0.7315 & 0.036 \\
\hline & $\mathrm{BS}\left(H_{8}\right)$ & 0.589 & 0.1114 & 0.0576 & 0.0025 & 0.2124 & 0.0091 & 0.73 & 0.0312 \\
\hline & $\mathrm{SS}\left(H_{9}\right)$ & 0.754 & 0.1096 & 0.0562 & 0.003 & 0.2204 & 0.0119 & 0.7234 & 0.039 \\
\hline \multicolumn{4}{|c|}{$\begin{array}{l}\text { Standardized comprehensive comparative } \\
\text { indicators (SCCIs) }\end{array}$} & & 0.0696 & & 0.2559 & & 0.6745 \\
\hline
\end{tabular}

\section{Conclusions and Recommendations}

To effectively and efficiently explore the most critical determinants of online-course sensor technology in the post-COVID-19 era, we creatively cross-employed the qualitative and quantitative analyses of MCDM methodology to systematically cross-evaluate the online and sensor technologies by an in-depth analysis of 150 current online-course users and 25 professional experts with the highest research reliability, validity, accuracy, and representativeness. According to Table 8, the three highest evaluated scores of the WHATs were RTF $\left(W_{10}\right)(0.0622)$, CPTF $\left(W_{9}\right)(0.0544)$, and CETF $\left(W_{7}\right)(0.0476)$, and the three highest evaluated scores of the HOWs were SS $\left(H_{9}\right)(0.039)$, MS $\left(H_{6}\right)(0.039)$, and ES $\left(H_{5}\right)(0.0389)$. The three most valuable and contributive conclusions of this study are as follows:

1. The RTF of online-course technology can combine SS, MS, and ES technologies to directly detect moving objects through face-sensor technology to stimulate learning emotions and motivate online-course participants to increase their learning performance.

2. The CPTF of online-course technology can merge SS, MS, and ES technologies to strengthen online-course hardware sensor devices and equipment to improve the depth and span of online-course content to strengthen online-course learning performance. 
3. The CETF of online-course technology can consolidate SS, MS, and ES technologies to not only exhaustively and empirically evaluate online-course implementation (e.g., face recognition sensors to monitor valid online-course participants to replace traditional onlinecourse registration ) but also to indirectly appraise online-course learning performance (e.g., online-course participants' emotions and the use of ESs to sense intangible signals of learning instead of the use of traditional paper examinations).

Consequently, this research innovatively applied the students' self-regulation learning performance (individual cognition), the evaluation system of educational institutions (group belongingness), and corporate recognition and identification (social unity) as analytical perspectives of SLT. It also creatively cross-employed the FA approach of quantitative analysis and the HOQ-QFD method and ANP model of qualitative analysis to directly resupply the academic gaps in the educational doctrine and IoT and sensor-technology-related research fields. Looking into the future, there are still more analytical perspectives and evaluated theories and models that can be utilized to inquire more deeply into the use of sensor technologies in online courses by applying the results of this research.

\section{Acknowledgments}

This research was supported by research support projects of the Ministry of Science and Technology (MOST 109-2221-E-005-049-) and National Taichung University of Education (NTCU109105).

\section{References}

1 M. Y. Hsieh: Eu. J. Math. Sci. Tech. 12 (2016) 25. https://doi.org/10.12973/eurasia.2016.1504a

2 K. Umino, M. Habara, and K. Toko: Sens. Mater. 24 (2012) 10. https://myukk.org/SM2017/article.php?ss=764

3 D. M. Naranjo, J. R. Prieto, G. Moltó, and A. Calatrava: Sensors 19 (2019) 2952. https://www.mdpi.com/1424$\underline{8220 / 19 / 13 / 2952}$

4 A. Baldominos: Sensors 19 (2019) 1910. https://www.mdpi.com/1424-8220/19/8/1910\#cite

5 H. Cornide-Reyes, R. Noël, F. Riquelme, M. Gajardo, C. Cechinel, R. Mac Lean, C. Becerra, R. Villarroel, and R. Munoz:. Sensors 19 (2019) 3291. https://www.mdpi.com/1424-8220/19/15/3291\#cite

6 M. Y. Hsieh: Eu. J. Math. Sci. Tech. 13 (2017) 3189. https://doi.org/10.12973/eurasia.2017.00712a

7 Y. K. Chan, M. Y. Hsieh, C. F. Lee, and C. C. Huang: Eu. J. Math. Sci. Tech. 13 (2017) 2645. https://doi. org/10.12973/eurasia.2017.01245a

8 Y. M. Huang and M.Y. Hsieh: Sustainability 12(2020) 2071. https://doi.org/10.3390/su12051806

9 M. Y. Hsieh: Com. Ele. En. 51 (2016) 376. https://doi.org/10.1016/j.compeleceng.2015.12.013

10 M. Y. Hsieh: J. Am. In. Hu. Com. 9 (2018) 307. https://doi.org/10.1007/s12652-016-0375-2

11 M. Y. Hsieh: J. In. Tech. 19 (2018) 225. https://doi.org/10.3966/160792642018031902022

12 Y. M. Huang, M. Y. Hsieh, and M. Usak: Mathematics 8 (2020) 897. https://doi.org/10.3390/math8060897

13 M. Y. Hsieh: Sustainability 12 (2020) 339. https://doi.org/10.3390/su12010399

14 M. Y. Hsieh: Eu. J. Math. Sci. Tech. 4 (2018) 1945. https://doi.org/10.29333/ejmste/83608

15 M. Y. Hsieh and M. Usak: Revista de Cercetare si Interventie Sociala 68 (2020) 95. https://doi.org/10.33788/ rcis. 68.7

16 J. Cohen: Social Learning Imitation Na. 156 (1945) 515. https://doi.org/10.1038/156515a0

17 D. M. Messick, H. A. M. Wilke, M. B. Brewer, R. M. Kramer, P. E. Zemke, and L. Lui: J. Pers. Soc. Psychol. 44 (1983) 294. https://www.gsb.stanford.edu/faculty-research/publications/individual-adaptations-structuralchange-solutions-social-dilemmas

18 A. Bandura: Recent Trends in Social Learning Theory (Academic Press, New York, 1972). https://www. elsevier.com/books/recent-trends-in-social-learning-theory/parke/978-0-12-545050-8 
19 J. Rezaei: Omega 53 (2015) 49. https://doi.org/10.1016/j.omega.2014.11.009

20 B. E. Engelhardt and M. Stephens: PLoS Genet. 6 (2010) e1001117. https://doi.org/10.1371/journal.pgen.1001117

21 J. Tapke, A. Muller, G. Johnson, and J. Siec: House of Quality (Iowa State Univ., 2003). https://web.archive.org/ web/20031105103546/http://www.public.iastate.edu/ vardeman/IE361/f01mini/johnson.pdf

22 P. T. W. Lee, J. Z. Wu, K. C. Hu, and M. Flynn: Int. J. Ship. Transport Logist. 5 (2013) 390. https://doi. org/10.1504/IJSTL.2013.055276

23 A. Mardani, A. Jusoh, E. K. Zavadskas, F. Cavallaro, and Z. Khalifah: Sustainability 7 (2015) 13947. https:// doi.org/10.3390/su71013947

24 M. Faisal, A. Bourahma, and F. AlShahwan: J. King Saud Univ. - Comput. Inf. Sci. 19 (2019) 4155. https://doi. org/10.1016/j.jksuci.2019.06.015

25 R. R. Kumar, B. Kumari, and C. Kumar: Cluster Comput. 2020 (2020) 1. https://doi.org/10.1007/s10586-02003166-3

26 L. Sun, J. Ma, Y. Zhang, H. Dong, and F. K. Hussain: Future Gener. Comput. Syst. 57 (2016) 42. https://doi. org/10.1016/j.future.2015.11.025

27 O. François and F. Jay: Nat. Commun. 11 (2020) 4661. https://doi.org/10.1038/s41467-020-18335-6

28 J. R. Hauser: Sloan Manag. Rev. 1 (1993) 61. http://web.mit.edu/hauser/www/Papers/How_Puritan-Bennett.pdf

29 T. L. Saaty: Commun. Oper. Res. Soc. Jpn. Special Issue on AHP 44 (1999) 6. http://gnedenko.net/Personalities/ Saaty/Saaty Thomas.htm

30 T. L. Saaty: Rev. R. Acad. Cienc. Exact. Fis. Nat. (J. Span. Aca. Sci.) 93 (1999) 395. http://docplayer. net/14799493-Thomas-1-saaty-education.htm

31 Y. K. Chan, M. Y. Hsieh, and M. Usak: Sustainability 13 (2021) 2203. https:// doi.org/10.3390/su13042203

32 M. Usak, M.Y. Hsieh, and Y. K. Chan: Sustainability 12 (2021) 1806. https:// doi.org/10.3390/su12051806

33 M. Duran, M. Usak, M.Y. Hsieh, and H. Uygun: Rev. de Cercet. si Interv. Soc. 72 (2021) 9. https://doi. org $/ 10.33788 /$ rcis. 72.1 